\title{
Human Resource Sustainability in the Hospitality Sector
}

\section{Mrunali Mehta ${ }^{1}$, Dr. Mukesh Kumar Mahawar ${ }^{2}$, Dr. Pradeep Kumar Mishra ${ }^{3}$}

1MBA Student, Madhav University, Abu Road, Rajasthan, India

${ }^{2}$ Associate Professor, Head, Faculty of Commerece \& Management, Madhav University, Abu Road, Rajasthan, India

${ }^{3}$ Assistant Professor, Faculty of Commerece \& Management, Madhav University, Abu Road, Rajasthan, India

Article Info

Volume 8, Issue 3

Page Number: 171-177

Publication Issue :

May-June-2021

\section{Article History}

Accepted : 15 May 2021

Published: 23 May 2021

\section{ABSTRACT}

In India's hospitality sector, Delhi is a resource provider. Sustainable human resource practices are important for the development of this sector. According to research findings, there is a scarcity of research on sustainable Human resource practices in Delhi's hospitality sector. This study focuses on sustainable human resource practices in the hospitality sector in Delhi, India. The research aims at dependent variable from the Sustainable Human Resource Management survey that deal with the role of humans in socioeconomic, societal, and business sustainability. The research presents empirical evidence regarding the importance of external Human Resource Management variables such as ethical principles (EP), employment (E), pay and benefits (PB) on the long-term sustainability of the Delhi hospitality sector. The research was carried out in hotels across Delhi. After validating the normalcy and trustworthiness of 48 responses, the statistical analyses were performed. Three hypotheses were formulated and test statistics were used to evaluate findings. With the exception of well-being to recruitment (0.09) and involvement to recruitment $(0.16)$, all factors had a strong positive association.

Keywords : Sustainable Human Resource Management; Hospitality sector; Delhi

\section{INTRODUCTION}

In the domain of Human Resources, sustainability has received a lot of attention recently for being a significant driver in establishing and attaining effective company plans (Garg 2014). Different stakeholders who stressed the importance of sustainability solutions support sustainability initiatives. Quasi groups, authorities, legislatures, societies, business, and, most significantly, customers are among them. Sustainability policies necessitate time, money, and, most significantly, the Human Resource Manager's commitment to their adoption. A major function of sustainable Human Resource Management (HRM) is aligning business goals with the objective of integrating sustainability into the organization. The objective of this paper is to examine at how long-term human resource management might help turn these obstacles into economic capabilities. It is impossible to overstate the 
significance of the HR organizational structure in attaining success in a sustainability-driven organization. According to studies, "sustainable practices permeate all facet of doing business and therefore must be ingrained across a company at all levels, transforming into a continual organizational

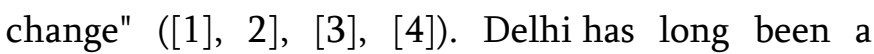
popular tourist destination for those seeking a sense of India's world class amenities. The state, Delhi is famed for its illustrious history and aristocratic image. The state's allure is enhanced by the numerous traditions and mythology that surrounds it, attracting tourists, researchers, and pilgrims from across world ([5], [6], [7], [8]). Important tourist attractions in Delhi includes Akshardham, Hauz Khas, Chandni Chowk, Red Fort, India Gate, Connaught Place, Dilli Haat, Qutub Minar, Humayun's Tomb, Lotus Temple, National Rail Museum, Rastrapati Bhavan, and Agrasen ki Baoli."

\section{Problem Statement}

Considering the increasing emphasis on social responsibility and sustainable Human resource management, there seems to be no indication of sustainable Human resource management in Delhi's hospitality industry. Delhi's expanding popularity as a tourism destination necessitates that the sector be prepared to use sustainable Human resource management practices in order to achieve efficient economic growth. This study was aimed to provide quantitative evidence regarding the importance of external Human resource management variables such as ethical principles (EP), employment (E), pay and benefits $(\mathrm{PB})$ on the hospitality sector's long-term growth in Delhi.

\section{Purpose}

The study's purpose is to acquire empirical data on the impact of certain factors on long-term Human Resource Management in the Delhi hospitality business. To that purpose, the accompanying objectives are defined:

- To evaluate the impact of different factors on the hospitality sector's long-term Human Resource Management in Delhi.

- To consider the effect of exogenous variables such as ethical principles (EP), employment $(E)$, pay and benefits (PB) on the hotel industry's long-term growth in Delhi.

\section{Procedures}

Meta-analysis was used to screen the dimensions that influence long-term Human Recourses Management in the hospitality business. The investigation was conducted in a quantitative manner. The study is descriptive in character since the conceptions and frameworks emerged as the academic analysis and field work on the hospitality sector in Delhi progressed. The study's characteristics were obtained from the Sustainable Human Resource The study's characteristics were derived from the Human resource management assessment on Human resource policies and practices on corporate environmental sustainability, published in 2012. The data were analysed from the management of the hospitality sector using a standardized questionnaire with a 5-point Likert scale for statistical analysis.

\section{Hypotheses}

H01: ethical principles have little influence on longterm Human resource management.

H02: employment strategies have so little influence on long-term Human resource management.

H03: pay and benefits seems to have no influence on long-term human resource management.

\section{Results and Analysis}

\section{Statistics that are descriptive in nature}

The data set's descriptive statistical analysis were first analyzed. The given Table of demographic distributions provides an overview of the individuals' 
participation and cooperation in the project. The great majority of the responders were female (60.41\%), and also the most common age group was 15-35 years old. It's worth noting that Delhi's hospitality sector focuses primarily to the youth of today. It can be ascribed to the generation's multitasking capabilities and digital approach. The majority of responders $(64.58 \%)$ were in their very first year of employment, while at least $12.5 \%$ had worked in the hospitality business for more than five years. The large majority of those polled employed for five companies (56.25\%). When asked if their organization had sustainability reports strategies, $75 \%$ of those who responded said yes. $14.58 \%$ of those polled were unsure whether or not their company has a formal yearly sustainable development strategy. This could be due to the recent hires' lack of expertise. The statistical techniques revealed that the respondents are suitable for participation in the research.

Table 1. Demographic statistics

\begin{tabular}{|c|c|c|}
\hline Character traits & & (\%) \\
\hline \multicolumn{3}{|l|}{ Gender } \\
\hline Female & 29 & 60.41 \\
\hline Male & 17 & 35.42 \\
\hline \multicolumn{3}{|l|}{ Age } \\
\hline $15-35$ & 34 & 70.83 \\
\hline $35-45$ & 11 & 22.92 \\
\hline $45-55$ & 3 & 6.25 \\
\hline \multicolumn{3}{|c|}{ Experience in the workplace } \\
\hline $0-2$ years & 31 & 64.58 \\
\hline $2-5$ years & 11 & 22.92 \\
\hline$>5$ years & 6 & 12.5 \\
\hline \multicolumn{3}{|l|}{ Organization rating } \\
\hline$* * * * *$ & 27 & 56.25 \\
\hline$* * * *$ & 17 & 35.42 \\
\hline$* * *$ & 4 & 8.33 \\
\hline \multicolumn{3}{|c|}{ Is there a sustainability framework in place for your company each year? } \\
\hline Positive & 36 & 75 \\
\hline Negative & 5 & 10.42 \\
\hline Probably & 7 & 14.58 \\
\hline \multicolumn{3}{|c|}{$\begin{array}{l}\text { The theoretical frequencies } f_{i} \text { need to be computed as well as the associated } z-\text { scores } z_{i} \text {, for } i= \\
1,2, \ldots, 14 \text {. Observe that the theoretical frequencies } f_{i} \text { are approximated using the following } \\
\text { formula: } \\
\qquad f_{i}=\frac{i-0.375}{n+0.25}\end{array}$} \\
\hline
\end{tabular}




\begin{tabular}{|c|c|c|c|}
\hline \multicolumn{4}{|c|}{$z$-score. This iscomputed as } \\
\hline Position (i) & 5 (Asc. Order) & $f_{i}$ & $z_{i}$ \\
\hline 1 & 3 & 0.0439 & -1.708 \\
\hline 2 & 4 & 0.114 & -1.205 \\
\hline 3 & 5 & 0.1842 & -0.899 \\
\hline 4 & 6 & 0.2544 & -0.661 \\
\hline 5 & 7 & 0.3246 & -0.455 \\
\hline 6 & 11 & 0.3947 & -0.267 \\
\hline 7 & 11 & 0.4649 & -0.088 \\
\hline 8 & 17 & 0.5351 & 0.088 \\
\hline 9 & 17 & 0.6053 & 0.267 \\
\hline 10 & 27 & 0.6754 & 0.455 \\
\hline 11 & 29 & 0.7456 & 0.661 \\
\hline 12 & 31 & 0.8158 & 0.899 \\
\hline 13 & 34 & 0.886 & 1.205 \\
\hline 14 & 36 & 0.9561 & 1.708 \\
\hline \multicolumn{4}{|c|}{ 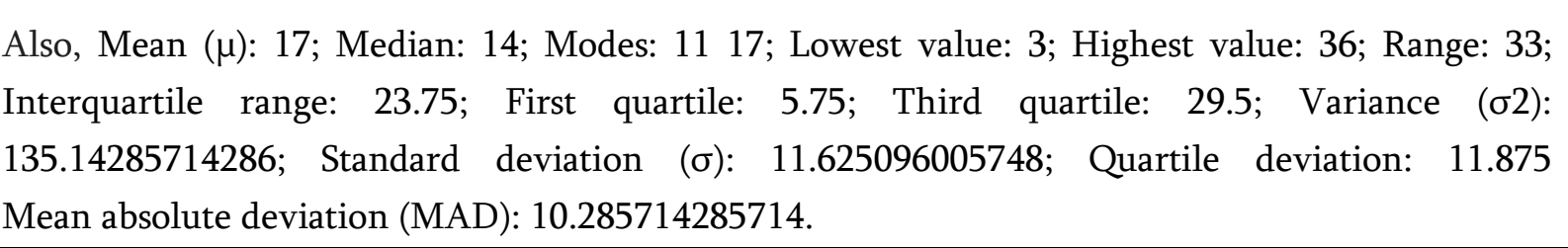 } \\
\hline
\end{tabular}

Table 2. The theoretical frequencies $f_{i}$ need to be computed as well as the associated $z$-scores $z_{i}$,

\section{Statistical Inference}

\section{The state of being normal}

As shown in the PP graph below, the values appeared regularly dispersed. A likelihood (P-P) graph was used to determine normalcy. The cumulative distribution results are compared against the theoretical CDF statistics in the PP graph. Is if specified theoretical dispersion is the proper model, the plot will be linearly proportional if such given dispersion meets the actual data. The graph in this research indicates that the proportion is a good fit to the observational data. The normal probability plot is obtained by plotting the $X$ - values (your sample data) on the horizontal axis, and the corresponding $z_{i}$ values on your vertical axis. The following normality plot is obtained: 


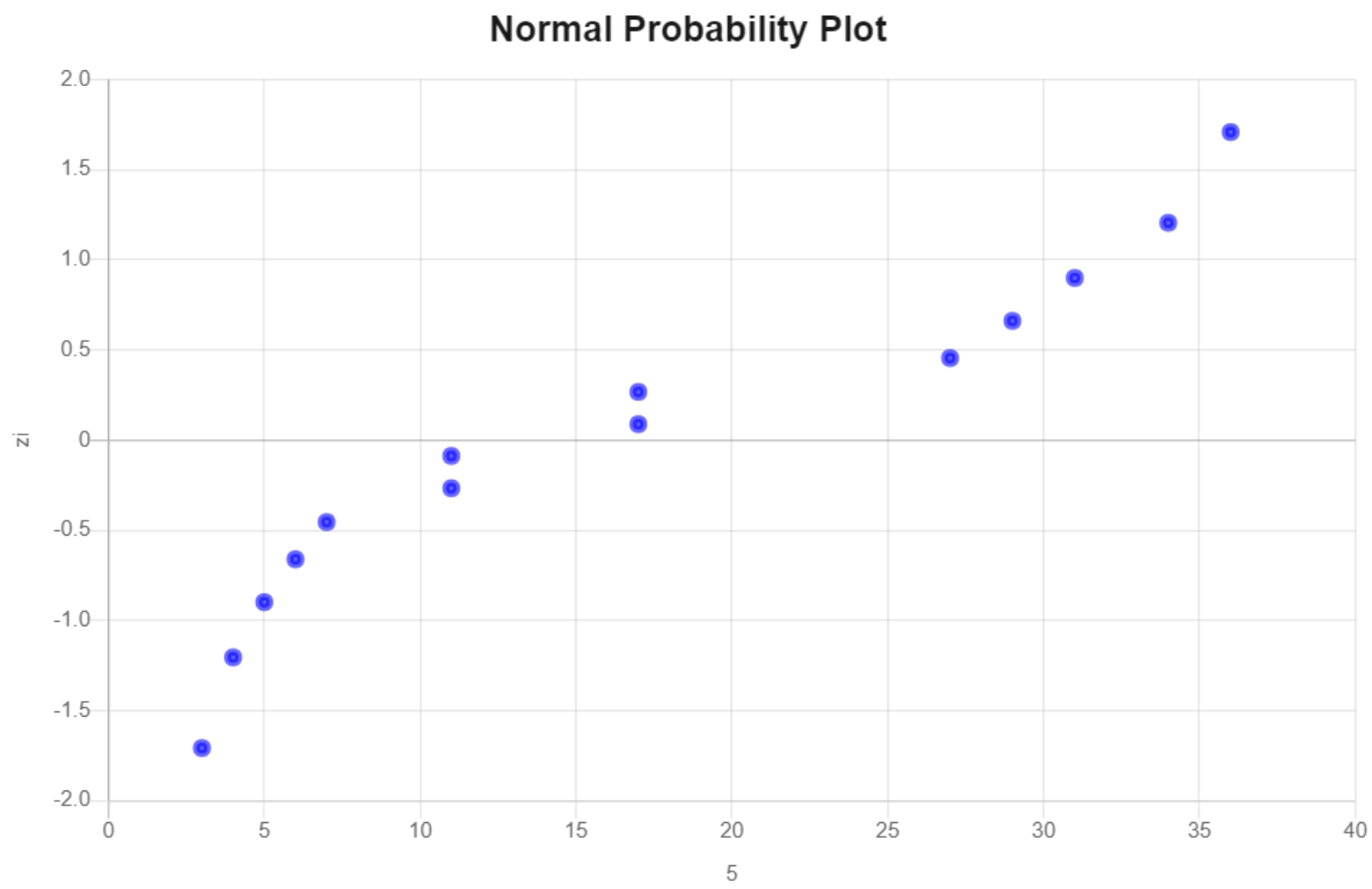

\section{Consistency of data}

The assessment has 15 questions on a Likert scale that needed to be answered. Cronbach's alpha was used to determine the structures' consistency. This is indeed a measure that verifies the questionnaire's logical reliability. The alpha coefficient ranges from 0 to 1 (on a scale of 1 to 5 , with 1 being inadequate and 5 being outstanding). A higher grade indicates that data interpretation is more reliable. According to Nunnally (1978), a dependability coefficient of 0.7 is adequate. Cronbach's alpha was 0.84 , indicating a high level of trustworthiness (Table 3).

Table 3. Consistency of data

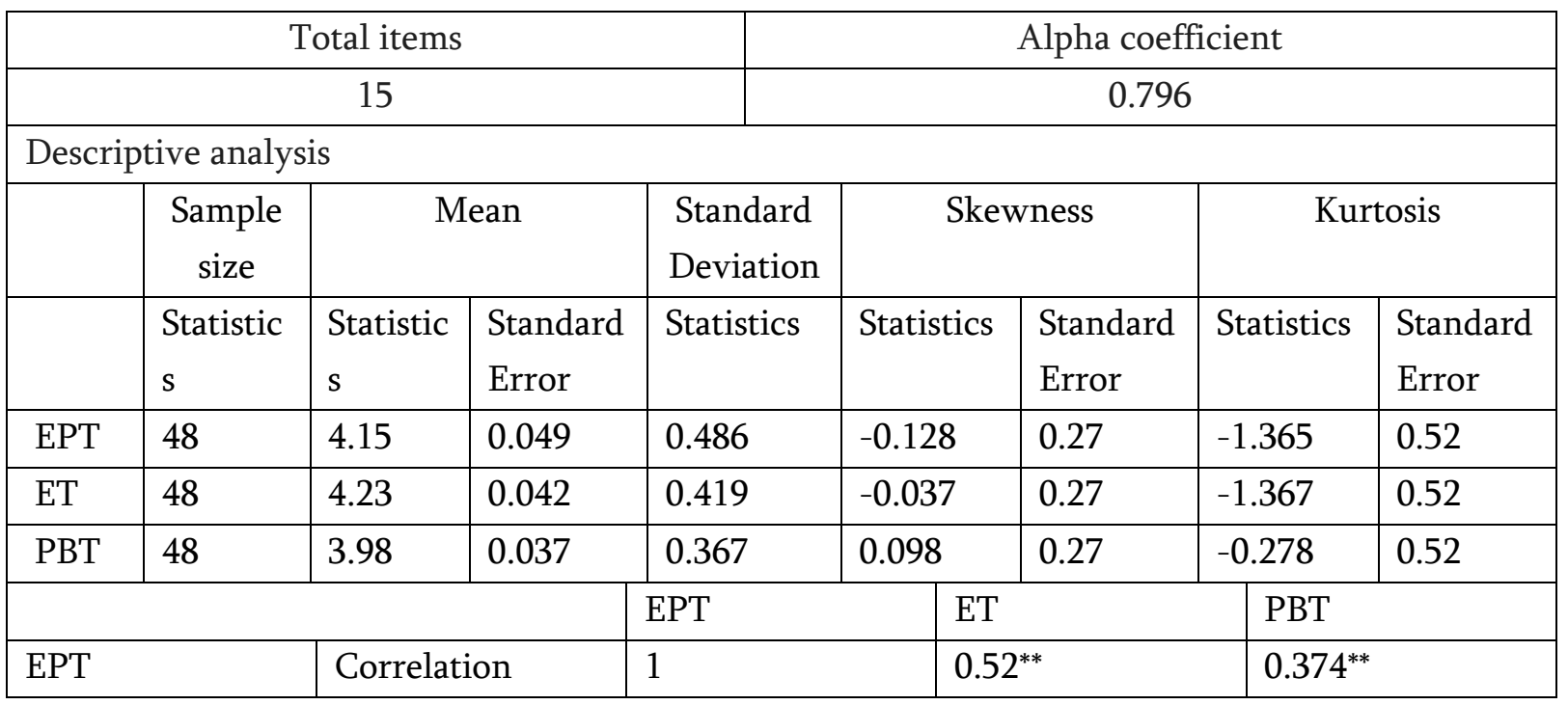




\begin{tabular}{|l|l|l|l|l|}
\hline & $\begin{array}{l}\text { Significance } \\
(2 \text {-tailed })\end{array}$ & & 0 & 0 \\
\hline \multirow{2}{*}{ ET } & Correlation & $0.52^{* *}$ & 1 & $0.314^{* *}$ \\
\cline { 2 - 5 } & $\begin{array}{l}\text { Significance } \\
(2 \text {-tailed })\end{array}$ & 0 & 0.0009 \\
\hline \multirow{2}{*}{ PBT } & Correlation & $0.374^{* *}$ & $0.314^{* *}$ & 1 \\
\cline { 2 - 5 } & $\begin{array}{l}\text { Significance } \\
(2 \text {-tailed })\end{array}$ & 0 & 0.0009 & \\
\hline
\end{tabular}

**Significance of correlation at the 0.01 level (2-tailed)

The above-mentioned correlation matrix demonstrates that almost all of the parameters have a substantial positive correlation.

\section{Testing Hypotheses}

After analyzing the relationships between the dependent variable, the impact for every factor was investigated. One sample t-tests, independent - sample t, and ANOVA were employed in this study. The significance of ethical principles (EP) on long-term human resource management is hypothesized as:

- $H_{0}$ 1: ethical principles have no substantial impact on long-term HRM.

- $H_{1} 1$ : Values and ethics have a substantial impact on long-term human resource management

The significance employment on long-term human resource management is hypothesized as:

- $H_{0}$ 2: Employment practices have almost no substantial impact on long-term HRM.

- $H_{1}$ 2: employment practices have a substantial impact on long-term HRM.

The significance of pay and benefits (PB) on long-term human resource management is hypothesized as:

- $H_{0}$ 3: pay and benefits have minimal impact on long-term HRM.

- $H_{1}$ 3: pay and benefits have a substantial impact on long-term HRM.

To see if the valuation and ethical score had an impact on overall HRM and was different from usual, a onesample t-test has been used. EP was determined as a number of 3.86 .

\begin{tabular}{|l|l|l|l|l|l|l|}
\hline & Sample size & Averge & $\begin{array}{l}\text { Standard } \\
\text { deviation }\end{array}$ & $\begin{array}{l}\text { Standard } \\
\text { error average }\end{array}$ & & \\
\hline EPT & 48 & 3.96 & 0.49 & 0.051 & & \\
\hline ET & 48 & 4.03 & 0.42 & 0.047 & & \\
\hline PBT & 48 & 3.83 & 0.38 & 0.049 & & \\
\hline & t-value & Degree of & Significance & Difference & Level of confidence \\
\hline
\end{tabular}




\begin{tabular}{|l|l|l|l|l|l|l|}
\hline & & freedom & & & \multicolumn{3}{l|}{$(95 \%)$} \\
\hline & & & & & $\begin{array}{l}\text { Lower } \\
\text { value }\end{array}$ & $\begin{array}{l}\text { Upper } \\
\text { Value }\end{array}$ \\
\hline EPT & 4.98 & 47 & 0.000 & 0.267 & 0.163 & 0.349 \\
\hline ET & 5.64 & 47 & 0.000 & 0.321 & 0.214 & 0.419 \\
\hline ET & 2.032 & 47 & 0.000 & 0.067 & -0.0214 & 0.126 \\
\hline
\end{tabular}

\section{IV.CONCLUSION}

With each and every seventh tourist in India visiting Delhi, the hospitality business in Delhi is a resources provider.

The purpose of this research was to see how certain variables affected the long-term Human resource practices of various firms in Delhi. This investigation yielded the following conclusions. The sustainability of human resource management analysis on Human Recourses's involvement in economic, societal, and sustainable development provided the latent variables for the analysis. Ethics, work opportunities, income, and benefits were the determinants. All factors had positive and significant relationships. Organizations should remain to be in charge of building recruitment systems that match their specific demands for longterm HR management. There are some limits to this current research, but it really does make a meaningful contribution. One of study's highlights is it's the first of its sort in Delhi, and it examined at particular characteristics and their impact on long-term HRM. All of the factors were found to have an impact on long-term HRM and strategies.

\section{REFERENCES}

[1]. Aghazadeh, S.M. (2003). The future of human resource management.Work Study, 52(4), 201207.

[2]. Baum, T. (2016). Sustainability and the Tourism and Hospitality. MDPI Sustainability, 21.
[3]. Cohen, T. M.-C. (2012). HRM's role in corporate social and environmental sustainability. VA: SHRM Foundation.

[4]. Foley, P. (2014). Ethics and HR Departments need to work together. Ethical Corporation.

[5]. Garg, B. (2014). Human resource-driving force of sustainable business practices. International Journal of Innovative Research and Development, 3(7), 378-382.

[6]. Gonçalves, S.P., \& Neves, J. (2012). The link between perceptions of human resource management

[7]. practices and employee well-being at work. Advances in Psychology Study, 1(1), 31-39.

[8]. Ybema, V. D. (2017). HR practices for enhancing sustainable employability: implementation, use, and outcomes. The International Journal of Human Resource Management.

[9]. Zaugg, R., Bulm A.,\&Thom, N. (2011). Sustainability in human resource management. IOP Press.

\section{Cite this article as :}

Mrunali Mehta, Dr. Mukesh Kumar Mahawar, Dr. Pradeep Kumar Mishra, "Human Resource Sustainability in the Hospitality Sector", International Journal of Scientific Research in Science, Engineering and Technology (IJSRSET), Online ISSN : 2394-4099, Print ISSN : 2395-1990, Volume 8 Issue 3, pp. 171-177, May-June 2021. Available at doi : https://doi.org/10.32628/IJSRSET218336 Journal URL : https://ijsrset.com/IJSRSET218336 